\title{
Chamantos, Ponchos y Balandres en Colchagua y Rancagua (siglos XVII-XIX)
}

\section{Chamantos, ponchos and Balandres in Colchagua and Rancagua (XVII-XIX centuries)}

\author{
Pablo Lacoste ${ }^{1}$ y Michelle Malén Lacoste Adunka²
}

\section{Resumen}

Se estudia la historia de ponchos, balandres y chamantos a partir de fuentes notariales y judiciales de Colchagua y Rancagua, desde comienzos del siglo XVII hasta mediados del XIX. Esta fuente aporta conocimiento relevante sobre la presencia de estos tejidos en la sociedad hispanocriolla, su valoración social y económica, sus ciclos históricos y sus características cromáticas. Se demuestra el profundo arraigo de la cultura del tejido dentro de la sociedad mestiza del Valle Central de Chile, y sus lazos con la tradición tejedora del mundo indígena. Se demuestra la existencia del chamanto desde la década de 1820 en esta región, base de la actual Denominación de Origen.

Palabras claves: chamanto, poncho, tejidos indígenas, artesanías chilenas, Denominaciones de Origen.

\begin{abstract}
We study the history of ponchos, balandres and chamantos from notary and judicial sources of Colchagua and Rancagua, from the early seventeenth century to the midnineteenth century. This source provides relevant knowledge about the presence of these tissues in chilean society, its social and economic value, its historical cycles and its color characteristics. It demonstrates the deep rootedness of tissue culture within the mestizo society of the Central Valley of Chile, and its ties to the tradition of the indigenous world. The existence of the chamanto from the decade of 1820 in this region, base of the current Denomination of Origin, is demonstrated.
\end{abstract}

Keywords: chamanto, poncho, indigenous fabrics, chilean handicrafts, Appellations of Origin.

Recibido: 22 octubre 2016. Aceptado: 19 abril 2017.

1 Profesor Titular Universidad de Santiago (Usach). Santiago. CHILE. Email: Pablo.lacoste@usach.cl

2 Profesora de la Universidad San Sebastián. Santiago. CHILE. Email: michelle.lacoste@uss.cl 
El chamanto y la manta corralera se han convertido en los tejidos emblemáticos de Chile. Reconocidos como denominación de origen en 2014, estos productos, elaborados actualmente en Doñihue, gozan de un prestigio sin precedentes: un chamanto alcanza un valor de 4 mil dólares, y se sitúa en el primer lugar dentro de los productos identitarios chilenos.

La valoración del chamanto y las mantas corraleras de Dońihue se enmarca dentro de la política del Instituto Nacional de Propiedad Industrial (INAPI), a través de su programa Sello de Origen, por el cual hace una década se ha comenzado a identificar y valorizar los productos chilenos en condiciones de ser reconocidos como DO (Denominación de Origen) o IG (Indicación Geográfica) (Belmar, 2016; Arancibia, 2016; Castro, 2016; Cofré, 2016; Aguilera, 2016). Se trata, en realidad, de un movimiento mayor, a escala latinoamericana, que también está presente en Brasil (Souza, 2014), Argentina (Champredonde y Cosiorovski, 2016; Carduza, Champredonde y Casabianca, 2016) y otros países.

Poco a poco se ha comenzado a redescubrir el valor de los productos típicos elaborados por los campesinos latinoamericanos durante varios siglos. En ese sentido, los chamantos y mantas corraleras de Doñihue son parte de un proceso mayor, a escala continental, signado por la recuperación del patrimonio cultural, alimentario y artesanal, del cual forman parte otros productos típicos como el tequila en México, el pisco en Perú y Chile, queso de Tafí del Valle, el queso de Chanco (Aguilera, 2016; Lacoste et al., 2014, 2015), el jamón de Chiloé (Mujica, 2017), la chicha de manzana (Castro, 2016), el pajarete del Huasco, el asoleado de Cauquenes y Concepción y el aguardiente cuyano (Lacoste, 2018), entre otros. Muchos de ellos nacieron en el siglo XVIII, con la madurez del Imperio español; alcanzaron su apogeo a mediados del XIX, y luego comenzaron a declinar. Algunos desaparecieron y otros lograron recuperarse, entre ellos, los chamantos y mantas corraleras de Dońihue.

La literatura especializada se ha interesado por el estudio de los tejidos tradicionales de la región, incluyendo ponchos y chamantos. Así se refleja en los trabajos de Cherduti y Nardi (1961), Corcuera (1999), Gruzmacher y Guajardo (2009),
Alvarado y Guajardo (2011), Pedrota, Tanquere y Endere (2013) y Castro et al. (2017). Estos textos han abordado el tema a partir de relatos de cronistas y viajeros del período colonial o de comienzos del siglo XIX, junto con fuentes iconográficas y colecciones de mantos y ponchos actualmente conservadas en los museos. También han realizado entrevistas a las actuales tejedoras y, en el caso de Castro et al. (2017), se han incorporado referencias nuevas de la prensa regional y los registros del INAPI. Como resultado, se han sentado las bases del conocimiento sobre el tema, particularmente útil para mostrar su profundo significado cultural. Esta tradición destaca que antes de la llegada de los españoles, los pueblos indígenas utilizaban tejidos cuadrados con una abertura en el centro para pasar la cabeza, prenda que con el tiempo comenzaría a llamarse "pocho". También se ha estudiado la manta mapuche trarikan makuñ y el sobremakun, poncho pequeño que se colocaba encima de otras vestimentas. A ellos se suman los íconos ñimin detectados en los actuales chamantos. El análisis de las fuentes iconográficas y las colecciones conservadas en los museos han permitido conocer las técnicas y los materiales empleados, y compararlos con los tejidos indígenas prehispánicos, conocidos a través de estudios arqueológicos. Uno de los temas más fascinantes es la conexión entre los actuales diseños de los chamantos y las antiguas tradiciones de los pueblos de la tierra.

Para profundizar en el tema, la presente investigación ha examinado un corpus documental inédito: los documentos notariales y judiciales de los siglos XVII-XIX. Naturalmente, esta fuente no incluye detalles de los diseños ni los sistemas simbólicos figurativos. Pero aportan otros datos, que también contribuyen a conocer el largo proceso de evolución histórica de estos tejidos, particularmente durante el período de dominación hispánica, cuando el Imperio europeo impuso sus costumbres y pautas culturales y a la vez tendió a invisibilizar y minimizar el valor del arte y las culturas originarias. Estas fuentes han sido escasamente tratadas para examinar este tema, hasta ahora. Particularmente los inventarios de bienes, tasaciones, testamentos y juicios en los cuales ponchos, chamantos y otros tejidos eran registrados como parte del patrimonio socioeconómico y cultural de los pueblos del espacio hispanocrio- 
llo. El estudio ha detectado referencias a los tejidos y ponchos en varios juicios criminales; a su vez, en los inventarios de bienes se registraron 119 telares, 216 ponchos, 55 balandranes y 63 chamantos en la zona de Rancagua y Colchagua, desde mediados del siglo XVII hasta mediados del XIX. Sobre la base de este corpus documental se ha elaborado el presente artículo.

\section{Balandres, ponchos y chamantos: definiciones conceptuales}

Entre los tejidos más relevantes detectados en las fuentes coloniales del Valle Central de Chile, se encuentra el balandre. Los españoles trasladaron a América esta denominación para una indumentaria de cambiantes usos.

En España medieval, el balandre era una "prenda rectangular con un orificio para meter la cabeza" (Menéndez Pidal, 1986 p. 71). Las referencias e ilustraciones de esta prenda fueron documentadas durante la vida del rey Alfonso X El Sabio (12211284), sobre todo en sus Partidas y en las miniaturas que ilustraron las Cantigas. Esta indumentaria tenía originalmente un perfil utilitario y modesto. No formaba parte de la ropa de la élite, salvo como medio de proteger prendas de mayor valor; era como un delantal, pero sin mangas. Por ejemplo, hacia 1304, el rey Jaime II de Aragón se colocaba un balandronet para afeitarse (Martínez Ferrando, 1962). La mayor parte de las referencias de uso del balandre corresponde a campesinos, como indumentaria de trabajo, o bien en ceremonias religiosas de carácter expiatorio, como símbolo de arrepentimiento y humildad. En los rituales de penitencia, estrictamente reglamentados por las Partidas, se mencionaba explícitamente esta prenda; el penitente debía vestir "escapulario a carona de la carne, hecho como balandre, habiendo una falda detrás y otra delante y con capirote o sin él" (Partida I, título VI). También lo usaban los campesinos para realizar sus labores, sobre todo pastores y labradores. El balandre servía de abrigo, y tenía la opción de coserle una capucha o caperuza para cubrir la cabeza; de este modo se podía continuar el trabajo en el campo, a pesar del frío, el viento y la lluvia. En las Cantigas se incluye una ilustración que representa a un labrador ata- viado con un balandre. Éste era como un poncho pequeño, colocado encima de otras vestiduras. La literatura especializada interpreta esta miniatura en los siguientes términos: "aldeano vestido con saya y encima, balandre, según uso de pastores y labradores" (Menéndez Pidal, 1986, p. 72).

Desde sus humildes orígenes, en los siglos XIII y XIX el balandre evolucionó en la sociedad medieval europea hacia niveles de mayor estatus. A comienzos del siglo XVIII, el Diccionario de Autoridades lo definía en los siguientes términos: "Vestidura talar ancha, que no se ciñe y por la parte que cubre los hombros penden de ella unas como mangas perdidas largas. Hácese de paño u otro género de lana, y usan de ella los colegiales y eclesiásticos dentro de casa, para su abrigo y comodidad" (DRAE, 1726, p. 534). Poco a poco, el balandre se alejaba de sus funciones utilitarias para los campesinos, para instalarse en la intimidad de las élites religiosas e intelectuales, como prenda confortable y propia de una parte privilegiada de la sociedad. Este fue el concepto que se desarrolló en América en el siglo XVIII, a fines del período colonial.

Al trasladarse a América, la tradición indumentaria española comenzó a interactuar con las culturas de los pueblos originarios, y surgió un mestizaje, tanto biológico como cultural. En este proceso de hibridización cultural, se desarrolló la cultura textil y se produjo el entronque entre los balandres medievales espańoles y los tejidos indígenas, como la manta mapuche trarikan makun, y sobre todo el sobremakun. En este contexto se produjo, más tarde, el surgimiento del chamanto.

El concepto actual de chamanto ha experimentado una sensible evolución en el tiempo. La glamorosa y exclusiva prenda actual no ha representado lo mismo en etapas anteriores. Así se refleja en el Diccionario de Chilenismos de Zorobabel Rodríguez (1875), escrito en el siglo XIX, donde se define al chamanto en los siguientes términos: "Manta gruesa y burda que, a pesar de los muchos y buenos oficios que presta a los pobres que la usan, no merece el honor de que sus orillas y boca sean ribeteadas con vistosas huinchas de lana como los ponchos" (Rodríguez, 1875, p. 142). Evidentemente, en ese tiempo el chamanto era una prenda 
de inferior calidad que el poncho. A su vez, éste se encontraba por debajo de la categoría de las mantas. Así lo explica el mismo autor al definir al poncho: "Del araucano pontho, manta de tela burda de lana cuadrangular y con una abertura en el medio para meter en ella la cabeza. El poncho se diferencia de la manta en que aquél es más tosco y casi siempre más grueso que ésta" (Rodríguez, 1875, p. 382). Según estos conceptos, para la segunda mitad del siglo XIX existía una jerarquía clara entre las tres prendas: la manta ocupaba el lugar de mayor calidad, seguida por el poncho; el chamanto quedaba en el último escalón, como prenda de uso popular y escasa calidad.

Fuera de Chile, el concepto chamanto también ha sido objeto de interés por parte de los especialistas. El Diccionario del habla de los argentinos, editado por la Academia Argentina de Letras, define chamanto: "Del araucano chamal y manto. Manta de tejido rústico, propia de indumentaria araucana. Costumbres: de colores muy vivos, los chamantos suelen ser usados unos sobre otros, en forma superpuesta, para irlos cambiando en los incidentes de la corrida” (AAL, 2003, p. 202). Estos conceptos contrastan con la visión de la RAE, la cual define al chamanto en los siguientes términos: "Chile. Manto de lana fina con muchas listas de colores que usan los campesinos (DRAE, 1992, p. 634).

La comparación de estas definiciones muestra discrepancias notables. En Buenos Aires, el chamanto es asociado con el mundo indígena; en Madrid, con los campesinos. A su vez, la primera definición chilena lo evaluaba como tejido pobre, mientras que la RAE lo aprecia como de "lana fina". Esta dispersión de definiciones muestra la heterogeneidad del vestido, las diferentes condiciones sociales de los usuarios y las connotaciones que otorgó el tiempo y la geografía a estas prendas de vestir.

Las nociones de poncho y manta tienen definiciones más precisas, sobre todo en los diccionarios de regionalismos y folclóricos argentinos. Con frecuencia, ambos conceptos están unidos. En efecto, se define como poncho "manta de lana de forma cuadrangular o rectangular, por lo común tejida en telar criollo con lana de oveja o llama. Tiene una abertura central para pasar la cabeza y se sostiene sobre los hombros. Generalmente llega a cubrir las rodillas (Osán y Pérez, 2006, p. 662). También se lo define como "manta cuadrada de lana (oveja, alpaca, vicuńa, algodón, etc.) con una abertura en el centro por donde se saca la cabeza. Se fabrican generalmente en rústicos telares" (Coluccio, 1964, I, p. 380). Otra versión afirma lo central, con ciertos matices: "Prenda característica del atuendo criollo consistente en un rectángulo tejido en telar tradicional, de lana de oveja, llama, guanaco o vicuńa (estos últimos muy costosos ahora), con una abertura en el medio, por donde pasa la cabeza. Las puntas del poncho caen aproximadamente hasta las rodillas, aunque también se usan de diferentes largos. El poncho no le servía solo al gaucho para abrigarse del frío, la lluvia y el viento, sino también para defenderse en las peleas con cuchillo" (Gatica, 1995 , p. 250).

Desde el punto de vista de los usos sociales del poncho, la literatura coincide en destacar su transversalidad. No era una prenda privativa de un solo segmento social, sino común a las distintas capas sociales. "El poncho fue y es usado tanto por las personas de primera calidad como por la gente de condición humilde, sobre todo como prenda de montar" (Coluccio, 1964, p. 381).

Había un elemento funcional que contribuyó a la difusión y estandarización del poncho: su comodidad para realizar actividades ecuestres. "Esta prenda es muy conveniente para cabalgar porque deja los brazos libres y protege completamente el cuerpo. Cubre íntegramente al jinete y en la parte trasera, toda el anca del animal. Hace de sobretodo y en invierno resguarda del agua. Lo mismo es cobertor en la cama improvisada en los caminos y en el verano guarece de los rayos solares; se le emplea de mantel; es carpeta en el momento del juego y sirve de escudo arrollado al brazo, en las peleas a cuchillo" (Coluccio, 1964, p. 381).

Las sociedades campesinas, donde la cultura del caballo era importante, apreciaban el poncho por todas estas funciones. Particularmente útil resultaba a los arrieros, que debían viajar centenares de kilómetros para enlazar las zonas de producción con los mercados. 


\section{Del poncho al chamanto: el estado del arte entre los historiadores}

El chamanto es una evolución del poncho, palabra de origen araucano. El registro más antiguo del concepto poncho data de 1530 (Corominas, 2000, p. 468). En el Cono Sur de América, esta prenda fue detectada muy tempranamente por los cronistas, en el segundo tercio del siglo XVII. Alonso de Ovalle (1646) señaló que los indígenas usaban el macuñ, manta de lana de 1,20 m de largo, con apertura en el medio para pasar la cabeza. El mismo objeto fue reconocido y registrado poco después por Diego de Rosales (1674), el cual comenzó a usar por primera vez la palabra "pocho" para denominar esta prenda. En su viaje realizado entre 1712 y 1714, Amédée Frézier se asombró al ver recurrentemente el poncho como prenda usada por la población masculina en las colonias españolas, sobre todo en el Reino de Chile (Frézier, 1716). Lo mismo ocurría en la actual Argentina. En 1714 se registró una venta de dos ponchos realizada en Tandil por aucas (Garavaglia y Wentzel, 1989). Nótese que los aucas -probablemente promaucaes- eran indígenas de Rancagua y Colchagua. Desde el espacio indígena, el poncho se extendió hasta convertirse en la principal vestimenta masculina en Chile y Argentina en los siglos XVIII y XIX.

Los historiadores de la frontera coinciden en destacar que los ponchos, junto con el ganado y la sal, formaban la triada de los productos más importantes del comercio indígena con los hispanocriollos (León, 1990; Pinto, 2000; Carreño, 2009).

Se ha calculado que la venta de ponchos mapuches a Chile llegaba a 100 mil unidades por año. El notable dominio técnico alcanzado por los indígenas para elaborar los ponchos les permitió competir con los tejidos británicos que comenzaron a inundar los mercados latinoamericanos después de la independencia, aprovechando las ventajas comparativas de la primera revolución industrial. Hasta la mitad del siglo XIX, los ponchos indígenas lograron mantener su mercado, a pesar de la asimetría tecnológica (Llorca, 2014).

La notoria calidad de los tejidos indígenas impulsó la admiración de viajeros y gobernantes. Algunos pensaron incluso la conveniencia de incorporar esos conocimientos para promover el desarrollo económico del Reino de Chile. Al respecto, el ya citado Higgins planteó la idea de estimular la migración de indígenas hacia el territorio hispanocriollo, para lograr que se asentaran allí y motorizaran la producción textil. Su plan era cerrar el comercio de ponchos de la Araucanía al Reino de Chile, de modo tal de causar la desocupación de los tejedores-y forzarlos así, a migrar hacia el norte (Lorca, 2014). Pero finalmente don Ambrosio desistió de este plan, y avanzó en la dirección contraria: en 1793 estableció un acuerdo de libre comercio con los indígenas, como forma de asegurar la paz en la frontera a partir de intereses comerciales y económicos compartidos (León, 1990, pp. 91-92).

Los estudios realizados hasta ahora sobre el poncho indígena han permitido conocer su relevancia y magnitud; su significado económico dentro de la sociedad indígena y su peso relativo dentro del intercambio comercial entre las naciones indígenas y los reinos españoles. También se ha señalado que los ponchos indígenas eran de alta calidad, tanto en comparación con las producciones criollas rioplatenses como respecto de los tejidos británicos. De todos modos, quedan muchos temas pendientes que aclarar, sobre todo el significado sociocultural, la calidad, los colores y los precios. Estos temas se examinan a continuación.

\section{Ponchos y mantas en la vida cotidiana}

La presencia de ponchos y mantas se hizo parte de la vida cotidiana en Chile en los siglos XVIII y XIX. Las fuentes originales de la época coinciden en destacar la relevancia de estas prendas en la región, particularmente los gobernantes e intelectuales. Ambrosio O'Higgins, el destacado gobernador de Chile y luego virrey del Perú, se refería en 1771 al "poncho y mantas fabricadas en tierras de los indios, el nombre que dan a una lana teñida de diversos colores que gasta toda clase de gente de la campaña de este Reino... una especies de mantas con la variación de lanas y listas y una abertura en el medio". ${ }^{3}$ Según

3 Ambrosio O'Higgins a Francisco Javier de Morales, 1771. Archivo Nacional Histórico de Chile (AN), Fondo Vicuña Mackenna, vol. 394, D. 
el gobernador Manuel de Amat y Junient, también después virrey del Perú, "su frecuente labor es en las indias tejer ponchos y mantas y los indios trabajar en labrar algunos platos y vacías de madera grandes que llaman rales" (Amat, 1760, p. 370). Ignacio Molina, el afamado cronista y sabio jesuita expulso, observó por su parte en el Compendio: "Las mujeres fabrican mantas de varios colores. Los hombres se aplican a tejer bellísimos cestos y hacer bellas obras de madera, de plumas o de pieles, que son muy buscadas de sus vecinos. Todos los ańos entran en las confinantes provincias españoles, donde tienen una especie de feria que suele durar 15 o 20 días... son habilísimos en el trato y difícilmente se dejan engañar" (Molina, 1776, p. 265).

Los pueblos indígenas se destacaban tanto en la elaboración de los tejidos como en su comercialización. Esta actividad se instaló en el centro de la agenda política, económica, militar y judicial del Reino de Chile. En 1723, con motivo del levantamiento mapuche del toki Vilumilla, se argumentó que entre las causas del movimiento estaba "haber atravesado algunos cabos de la Concepción los ponchos que venden los indios bravos, y estancado el vino y otras cosas...". ${ }^{4}$ Por esa razón, en los acuerdos que pusieron fin a la rebelión, las autoridades dispusieron que"[se] proceda al castigo con toda severidad y rigor, no permitiendo que a los indios en su trato de ponchos y demás granjerías que tuviesen, se les haga agravio ni vejación, y antes si, procure fomentarlo y [incorporar a los] indios bravos que anduvieren en este u otros comercios". ${ }^{5}$ En 1747, al discutirse el tema del comercio con las tribus mapuches, el auditor del ejército fronterizo opinaba que se debía ejercer mayor control sobre los buhoneros prohibiendo que "los españoles ni mestizos lo internen a la tierra adentro" forzando a que "los Indios que se salgan a las Plazas de las riberas del Biobio y lo compren en conchavo de sus ponchos ó a crédito de su buena correspondencia".

4 Cartas y expedientes del Gobernador de Santiago de Chile años 1707-1753, f. 807.

5 Carta del Arzobispo de La Plata, virrey del Perú, a S.M. el Rey, Lima, 2 de julio de 1723. Biblioteca Nacional (BN), Manuscritos Medina, vol. 180-181, f. 144.

6 Voto o sentir del Contador Pedro de Robina, Concepción, 14 de noviembre de 1738. BN, Manuscritos Medina, vol. 184, f. 148 .
El poncho fue especialmente popular entre los grupos subalternos. De allí que durante el siglo XVIII aparecen diversos testimonios judiciales en los cuales el robo de ponchos figuró de modo prominente. En Loncomilla, en 1747, las autoridades dieron cuenta "que en la fiesta que se hizo en Putagán, inmediato al concurso de la gente, saltearon a Antonio Sagal y a Ignacio Roa, mocitos de veinte ańos, que a palos los dejaron por muertos y los robaron sus ponchos, sombreros y pańuelos...". 7 Uno de los autores de este robo declaró al ser capturado: "Es verdad que cometió el delito de haberlos robado por hallarse en tierra ajena y perdido en unos juegos que hubieron, en donde lo dejaron desnudo en pelotas [...] les llevamos los tres ponchos y un sombrero y un pañuelito musgo con flecos...”. ${ }^{8}$ En otro caso judicial que tuvo lugar en las cercanías de Tinguiririca, se manifestaba que el asesino de un cacique mapuche llevaba "dos ponchos, al parecer pehuenches, abalandronados, el de encima colorado con flecos y el de abajo azul sin ellos, y una botas verdes hechizas muy usadas, y el sombrero blanco ordinario [...]".?

El poncho y las mantas formaban parte de la vida cotidiana en el Reino de Chile, tanto entre los sectores populares como entre las élites. Ellos servían como objeto práctico, para vestirse y abrigarse; pero también tenían un singular valor sociocultural, como reserva de valor y símbolo de prestigio. El poncho era objeto del deseo; por él se comerciaba, se luchaba y se moría. Su prestigio se construyó a través de un largo proceso sociocultural, en el cual participaron otras prendas, como los balandres.

7 Auto cabeza de proceso dictado por el teniente de corregidor de la doctrina de Loncomilla capitán Esteban de Oses, El Sauce, 14 de noviembre de 1747. Causa Criminal contra José Medina, Bartolomé Sánchez y Pedro Pineda por salteadores. AN, Fondos Judiciales de Talca (FJT), Leg. 226, pza. 25.

8 Confesión de Juan José Medina ante el teniente de corregidor Esteban de Oses, El Sauce, 22 de noviembre de 1747. Causa Criminal contra José Medina, Bartolomé Sánchez y Pedro Pineda por salteadores. AN, FJT, Leg. 226, pza. 25.

9 Causa criminal contra Joseph Ortiz, Concepción, 1 de marzo de 1766. AN, Fondo Real Audiencia (FRA), vol. 1684, f. 28. 


\section{El balandre o balandrán como indumentaria hacendal criolla (1736-1840)}

El balandrán ocupó un lugar de honor entre los vecinos del Cono Sur de América, signado por sus colores, sus elegantes diseńos y la calidad de sus terminaciones. Durante un siglo, esta prenda fue sinónimo de tejido de la más alta calidad. Sirvió a las élites para distinguirse socialmente, y a los artesanos para empeñarse en lograr tejidos de mejor factura y más elevado precio. Además, el balandre (llamado también balandrán) sirvió para establecer estándares de calidad superior en otros tejidos, como por ejemplo, los ponchos.

El último gobernador realista del Reino de Chile, Francisco Marcó del Pont, usaba balandre y chamanto con sombrero de jipijapa o de paja. Un coronel del Ejército de los Andes lo recordaba así: "vestía un uniforme de teniente general, calzón corto, medias de seda de patente, zapatos de terciopelo con hebillas de oro, un ponchito corto por encima y un sombrero muy fino de jipijapa" (Pueyrredón, 1862, p. 178). Después de la batalla de Chacabuco, Marcó del Pont huyó hacia el litoral, y unos días después fue capturado en San Antonio, vestido con ese tipo de prenda: "le encontraron envuelto en un poncho balandrán y un disforme sombrero de paja" (Espejo, 1876, p. 580).

En el espacio rioplatense pampeano, los "ponchos balandranes" eran una de las modalidades que adoptaron los tejidos de Santiago del Estero, productos de mayor calidad que los de la zona central (Córdoba y San Luis). Así lo ha señalado la literatura especializada (Garavaglia, 1986; Garavaglia y Wentzel, 1989). En Chile, por su parte, los balandranes también tuvieron una presencia importante, como objetos en sí mismos, o bien como adjetivo calificativo de una variedad de ponchos (ponchos balandres).

En las fuentes compulsadas en los corregimientos de Colchagua y Rancagua, los balandranes estuvieron presentes desde 1736 hasta 1840 . En ese período se registraron 55 unidades. $\mathrm{Al}$ observar sus precios, se detecta que el balandrán era la prenda más valiosa de la casa. Era parte del patrimonio familiar: se declaraba como bien incorporado al matrimonio; se atesoraba durante toda la vida, y luego, se transmitía en herencia.

El balandrán se destacaba por sus terminaciones y sus colores. Los registros indican el color de 35 ejemplares; los más frecuentes eran los balandranes blancos $(18$ casos $=51 \%)$ y los azules $(14$ casos $=$ $40 \%)$. En menor medida aparecieron también balandranes colorados (3 casos $=8 \%$ ). Los balandranes blancos representaban mejor la austera tradición española, mientras que los azules y colorados mostraban la vivacidad colorida del mundo indígena y criollo. Poco a poco, las culturas locales comenzaban a apropiarse de los objetos europeos, mestizando sus aspectos más fundamentales.

Los precios eran un reflejo del estatus social alcanzado por los balandranes. En la composición del valor de cada uno, influían principalmente dos factores: antigüedad y calidad. Los balandranes antiguos y muy viejos se tasaban a 1 o 2 pesos. Los viejos oscilaban entre 3 y 7 pesos. Los usados variaban entre 8 y 18 pesos. Y el valor de los nuevos comenzaba desde los 10 pesos (sin aliño) y podían alcanzar hasta 47 pesos cuando eran balandranes de labor, bien trabajados. En los inventarios de bienes se incluían también balandranes sin terminar: uno a medio tejer se tasaba en 11 pesos; y los hilos de un balandrán se valoraron en 10 pesos.

Estas elevadas cotizaciones reflejan la apreciación que alcanzaba el balandrán en la sociedad criolla del Cono Sur de América. El balandrán tope de gama, tasado en 47 pesos equivalía en valor prácticamente a 10 vacas. Se formaba así una pareja de prendas que realzaba la pareja del hacendado y su esposa, con balandrán y mantilla de bayeta de Castilla, tasados respectivamente a 47 y 40 pesos. Las élites los demandaban porque el balandrán y la mantilla permitían realzar la personalidad de la pareja portadora, la rodeaban de prestigio y reconocimiento social. Eran símbolos de estatus y autoridad.

Desde el punto de vista del desarrollo de la artesanía textil de alta calidad, la preferencia de las élites por estas prendas dio a las tejedoras la oportunidad de esmerarse a través de un trabajo cuidado y creativo, 
por medio del cual lograban desplegar sus cualidades artísticas.

El balandrán se convirtió en un símbolo de trabajo intensivo y de oficio transmitido de generación en generación en el espacio que brindaba el taller casero o doméstico. Fue un medio adecuado para canalizar las energías creativas de los campesinos, y de jerarquizar y valorizar sus trabajos. Se instaló así, en los imaginarios sociales, un producto tejido por el medio local, con gran reconocimiento de parte de los mercados, sobre todo de las élites. De este modo se sentaron las bases para una sólida cultura artesanal de índole familiar y se aseguró la futura evolución del chamanto.

\section{Ponchos criollos e indígenas en el Cono Sur}

Dejando de lado los aristocráticos balandranes, llega el momento de abordar el tema del poncho indígena. Como se ha señalado, los viajeros y cronistas coinciden en destacar que esta prenda fue de uso universal en la población masculina de Argentina y Chile, desde comienzos del siglo XVIII hasta mediados del XIX. Era transversal a todas las capas sociales, las cuales se diferenciaban por la calidad de la prenda.

La amplia demanda de ponchos por parte de la sociedad hispanocriolla generó segmentos por calidad y precio. Los ponchos más baratos eran elaborados en el espacio rioplatense-pampeano, sobre todo en Córdoba y San Luis y tenían un valor de un peso por unidad. Algo mejores eran los de Santiago del Estero, cuyos precios oscilaban entre los 3 y 12 pesos; estaban adornados con vistosos colores y dibujos; se denominaban "balandranes", "calamacos" y "mestizos", estos últimos por mezclar lana y algodón. Finalmente estaban los ponchos indígenas, de trama muy apretada, impermeables a la lluvia, calidad y precio superior. Miles de unidades se remitían cada año a esos mercados entre mediados del siglo XVIII y mediados del XIX (Garavaglia, 1986; Garavaglia y Wentzel, 1989, pp. 217-218).

En Chile, el interés por la posesión de ponchos y el valor que éstos tenían quedó expuesto en varias instancias. Al respecto, diversos expedientes judiciales proporcionan valiosos datos sobre el valor que le asignaba la gente, en particular cuando el poncho ya era universalmente usado. En 1766, en las cercanías de Tinguiririca, se registra el cambio de tres caballos por un poncho. ${ }^{10}$ En 1780, se levantó una causa judicial por el sueldo impago de un peón, al cual se "le prometió que le daría por su trabajo un poncho...". ${ }^{11}$ En cuanto al valor en pesos, durante un proceso ventilado contra un vagabundo en Talca, acusado del robo de caballos, se sostuvo que la principal prueba acusatoria consistía en que había intentado cambiar los animales "por un poncho: siendo así que dichos caballos valdrán más de treinta pesos...". ${ }^{12} \mathrm{El}$ reo, negando el delito, confesó que uno de los caballos lo había adquirido en Ningüe a cambio de "un poncho negro y una manta listada negra y un cuchillo grande y una faja". ${ }^{13}$ Pedro Solís, de Talca, denunció en 1772 el robo de unas yeguas que, según él, "se las había dado Joseph Altones por un poncho colorado". ${ }^{14}$

No sorprende que los ponchos fuesen atractivos para el peonaje. En efecto, desde la perspectiva de la calidad, los ponchos indígenas eran los que alcanzaban niveles superiores tanto en precio como en estimación. Eran impermeables y resistentes al agua, ideales para zonas lluviosas; tenían diseños atractivos, con colores bellos y durables; además, sus hilos de lana aseguraban una larga vida útil.

El precio de los ponchos indígenas es todavía un tema que descansa en fuentes poco sistemáticas. Garavaglia señala que alcanzaban precios elevados, pero no entrega datos precisos. Llorca (2014) menciona

10 Causa criminal contra Joseph Ortiz por el homicidio de dos caciques de Boroa, Concepción, 1. de marzo de 1766. AN, FRA, vol. 1684, f. 19.

11 Juan Merillanca contra Dionisio Basoaldo, Los Maitenes, doctrina del Maule, 20 de junio de 1780. AN, FRA, vol. 1109, pieza 2, f. 31.

12 Causa criminal contra José Molina por ladrón y vago, San Antonio de Talca, 22 de febrero de 1775. AN, Fondo Judiciales de Puchacay (FJP), vol. 15, pieza 51.

13 Causa criminal contra José Molina por ladrón y vago, San Antonio de Talca, 22 de febrero de 1775. AN, Fondo Judiciales de Puchacay (FJP), vol. 15, pieza 51.

14 Causa criminal contra Tiburcio Suazo por abigeato, San Antonio de Talca, 10 de agosto de 1772. ANH, FJP, vol. 15, pieza 49. 
tres registros de precios. El primero corresponde a Luis de la Cruz (1806), conforme al cual un poncho indígena equivalía a 16 yeguas. Estimando un valor de 5 pesos por cabeza, el poncho tendría un precio de 90 pesos. En 1840 se refiere otro cálculo de un pocho por entre 15 y 20 yeguas, lo cual llevaría su precio entre 75 y 100 pesos. Poco tiempo después el viajero alemán Maas calculó el valor de un poncho por un caballo y tres vacas, lo cual rondaría los 20 pesos. O'Higgins, en el comentario ya citado, proponía en 1771 que se impusiera un impuesto de "tres a cuatro pesos sobre cada uno fabricado en tierra de indios", lo cual proporciona una idea del valor que tenían las prendas. Las cifras son altas, escasas y dispersas. Por ello, resultan insuficientes para establecer un patrón. En todo caso, no quedan dudas de la superioridad del poncho indígena sobre los ponchos hispanocriollos del espacio rioplatense.

En el terreno de los colores, singular relevancia alcanzó en el norte de Argentina el poncho calamaco o colorado. El calamaco es el "poncho de lana teńida de rojo". A su vez el poncho salteño es un poncho colorado con franjas negras y flecos del color de la prenda" (Osán y Pérez, 2006, p. 662). Por contraste, el "poncho pampa", utilizado en la zona central de Argentina, "a diferencia de los ponchos calamacos, no entraba sino raramente el color rojo" (Coluccio, 1964 , p. 382). El autor agrega al respecto que "los ponchos pampas se caracterizaban por su repetición de cruces, por sus fajas en líneas longitudinales o por sus guardas gruesas, casi siempre distribuidas en blanco y negro, raras veces el amarillo y el verde" (Coluccio, 1964, p. 380). A diferencia de lo ocurrido en las pampas rioplatenses, en la Araucanía sí había ponchos verdes. Éstos tenían un nombre especial: se los llamaba "cari" derivación del mapudungún karü (verde).

El dominio de la técnica permitía a los artesanos obtener colores durables. Ésta era una de las principales cualidades de los ponchos, y fundamento de sus elevados valores de mercado según Llorca (2014). Para alcanzar esos colores, se requería un detallado conocimiento de los colorantes naturales, sobre todo a partir de fibras vegetales. "De la cochinilla, la achira, las flores de seibo, el algarrobo, obtenían el café oscuro; de la chilca, el aguaribay, el churqui y la pimpinela cimarrona, el amarillo; del añil, el azul y el celeste; del aromo, el gris; del piquillín, el morado. Los medios tonos constituían los verdaderos secretos de aquellas tejedoras sin pretensiones químicas" (Coluccio, 1964, p. 381).

\section{El ciclo histórico del poncho (1664-1850)}

El testimonio más antiguo detectado hasta ahora de presencia de ponchos en el actual territorio chileno, data del siglo XVII. Se trata de un informe elaborado para dar cuenta de las expediciones holandesas a la zona de Valdivia realizadas entre 1642 y 1643. La diferencia de lenguaje no permitió a los holandeses conocer el nombre de ese tejido ni llamarlo "poncho", pero lo describen con todos sus detalles. "Los hombres no llevan camisa ni chaleco, sino solamente una pieza del mismo género de que hacen los calzones, como de una yarda cuadrada, en la que practican una abertura para dar pasada a la cabeza y que les cubre las espaldas, dejando los brazos y las piernas libres" (Brouwer, 1646, p. 141). Ese mismo ańo, Alonso de Ovalle (1646) detectó la presencia de esta prenda, a la cual los indígenas llamaban macuñ, tal como ya se ha señalado.

La documentación relevada en la presente investigación ha permitido detectar el primer registro del concepto "pocho" en Chile, en la región de Colchagua. Corresponde a la casa de Diego Marín (San Fernando, 1664) donde se registraron tres ponchos. Este descubrimiento documental representa un hallazgo significativo, pues representa un adelanto en 10 ańos del registro más antiguo considerado hasta ahora por la literatura especializada. En efecto, de acuerdo a Alvarado y Guajardo (2011), el primer registro del concepto "pocho" correspondía al libro de Diego de Rosales (1674). Ahora tenemos una visión más completa y antigua de la presencia de esta prenda en la región. Desde allí se comenzó a expandir por todo el Valle Central. En la zona estudiada se registraron otros 110 ponchos en el siglo XVIII y 103 en la primera mitad del XIX. Ese largo período se podría llamar "el siglo y medio del poncho".

La distribución geográfica de los ponchos en el siglo XVIII muestra que el poncho se extendió por 
la totalidad del Valle Central. La fundación de las ciudades de San Fernando (1742) y Santa Cruz de Triana (Rancagua), en 1743 , generó polos importantes de demanda para estos tejidos. Cada una de estas ciudades concentró una decena de registros para esta centuria. Desde estas localidades, los ponchos penetraban hacia los mercados del oeste. Un circuito a línea se formó con los registros de Rengo, Malloa, Peumo (7136) y Armahue (1758) y Rapel (1730); otra ruta paralela corría más al sur, por San Fernando, Nancagua y el valle de Colchagua. En la centuria siguiente se registraron también ponchos en el secano y el borde costero, tanto en el sur (Bucalemu, 1803) como en el norte (Navidad, 1829). En poco más de una centuria, los ponchos estaban presentes en la totalidad de los corregimientos de Rancagua y Colchagua.

Los registros revisados confirman las percepciones de los viajeros y cronistas. Como se ha señalado en el estudio de Llorca (2014), los observadores coincidían en señalar la presencia notable de los ponchos como vestimenta típica en Chile. Los registros de los bienes inventariados en las casas confirman esas percepciones. Pero, a su vez, esta fuente aporta otros datos relevantes y complementarios desde el punto de vista cualitativo.

La influencia del prestigioso balandrán se hizo evidente en los ponchos de Rancagua y Colchagua. Como se ha señalado, los balandranes eran casi siempre blancos o azules. El 80\% de los casos registrados tenían estos colores. Pues bien, se nota una tendencia similar en los ponchos: el 76\% de estas prendas también se concentraban en esos dos colores: azul y blanco. Al parecer, las capas medias que compraban los ponchos trataban de tener prendas parecidas a los balandranes que usaban los grandes hacendados, al menos en el color.

Desde el punto de vista de los materiales, por lo general, las fuentes no entregan datos precisos. En el contexto cultural de la época, tal vez este silencio se deba a los usos y costumbres de asociar el poncho con los tejidos de lana. Durante el período colonial, desde el siglo XVII hasta comienzos del XIX, casi nunca se menciona la materia prima del poncho, salvo en dos casos: una vez se registró lana (1803) y la otra, algodón (1809). Después de la indepen- dencia, y coincidiendo con la expansión comercial británica en los mercados latinoamericanos, comenzaron a verse con mayor frecuencia los ponchos de algodón (siete casos entre 1823 y 1835). Posiblemente, esos ponchos de algodón reflejaron el intento de la industria textil inglesa de penetrar en el mercado chileno. De todos modos, estos registros fueron mínimos, dentro de una muestra total de 216 ponchos. Los ponchos tradicionales de lana lograron sobreponerse a la ofensiva comercial británica. Otra interpretación sería asociar esos ocho ponchos de algodón con las economías trasandinas, donde el algodón se cultivaba en la zona norte, desde Catamarca hasta el Paraguay. Esta referencia muestra también un lazo con la tradición de los ponchos de Santiago del Estero, donde se utilizaba tanto el algodón como la lana.

Dentro de las expresiones típicas de calidad de los ponchos, se usaban conceptos como: "abalandronado" y "frizado". Los de Rancagua y Colchagua aparecen cinco veces como "abalandronados" o "surtido de balandrón”. Se trata del mismo concepto detectado por Garavaglia para los ponchos santiagueńos. Por último, se menciona también un caso de un poncho "frizado", connotación que apuntaba a mostrar énfasis en el abrigo.

El color de los ponchos es otro elemento relevante. Las fuentes revelan el color del poncho en 64 registros. El más recurrente es el azul, registrado en 35 casos (54\%), lo que probablemente se vincula al profundo interés que mostraban los mapuches por el añil. "Ni que hayan querido baptizarse ningun parbulillo sin que les diesen añil”, observó el capitán Jerónimo Pietas en $1723 .{ }^{15}$ Siguen en importancia el blanco, con 13 casos (20\%) y el negro con nueve $(14 \%)$. También se registraron ponchos verdes ("cari") en cuatro oportunidades (6\%). El poncho colorado, típico de otras regiones como Salta, presenta solo tres casos (4\%).

Los registros detectados entregan información del precio de 106 ponchos, lo cual representa el 49\% del total de la muestra. De acuerdo al valor de tasación y la evaluación expresada por los notarios, los

15 Gerónimo de Pietas al Rey, Chillán, 3 de octubre de 1723. BN, Manuscritos Medina, vol. 309, fojas 42. 
ponchos se clasificaban en tres grupos: buenos, intermedios y viejos u ordinarios. Los buenos oscilaban entre 10 y 24 pesos; los intermedios entre 5 y 9 pesos; y los ordinarios o viejos entre uno y 4 pesos.

Naturalmente, en la base de la pirámide estaban los ponchos más baratos. Su bajo valor se explicaba por su antigüedad (viejos, muy usados) o su deterioro (rotos, maltratados, apolillados). Dentro de esta banda también se incluían los pochos de niños (tasados a 9 pesos la docena). Además, tres ponchos de algodón se encontraban en esta categoría. En total, dentro de este nivel de ponchos baratos se registraron 49 casos (46\%). Más frecuentes eran los ponchos de valor intermedio, con 45 ejemplares (42\%). En esta categoría aparecían los ponchos abalandronados aunque los ponchos pehuenches fueron más frecuentes. También se incluyeron cuatro ponchos de algodón. Finalmente, en la cúspide de la jerarquía se hallaban los ponchos buenos $(12$ casos $=11 \%)$. En el tope de gama se registró un poncho arribano de 24 pesos; de los dos de 20 pesos uno se caracterizó como "bueno" y el otro, "fino sin usar".

En el territorio estudiado, los ponchos tenían un valor superior al que alcanzaban en las pampas rioplatenses. Como se ha señalado, el valor normal de los ponchos de Córdoba y San Luis era de un peso. En Rancagua y Colchagua, por ese precio solo se podían conseguir ponchos de niños, o muy deteriorados. Los colchagüinos estaban más cerca de los ponchos santiagueños, cuyos valores oscilaban entre 3 y 12 pesos. De todos modos, en Rancagua y Colchagua había también ponchos de mayor calidad, que llegaban a duplicar el valor de los del Noroeste Argentino.

El precio de los ponchos muestra datos de interés. En primer lugar, dentro de la jerarquía de la indumentaria masculina local, el poncho aparecía como una prenda importante, pero inferior al balandrán. Como se ha señalado, el balandrán usado oscilaba entre 14 y 18 pesos, lo cual lo ubicaba cerca del poncho nuevo y bueno. Los balandranes ubicados en el tope de la gama superaban los 30 pesos, hasta llegar a 47 pesos. Había, por lo tanto, una escala jerárquica entre ambas prendas, con el balandrán en primer lugar y el poncho en posición subalterna.
Si se comparan estos ponchos con los del espacio rioplatense pampeano, se detectan conclusiones relevantes: los ponchos de Colchagua y Rancagua tenían mayor jerarquía que los ponchos de la zona central pampeana. Estos valían un peso y representaban el $85 \%$ de las exportaciones de ponchos al mercado de Buenos Aires. En cambio, los ponchos de ese valor, en la zona estudiada, apenas estaban presentes (solo un caso). En ese sentido, por equivalencia de precios y calidades (incluyendo los abalandronados), los ponchos colchagüinos estaban más cerca de los santiagueños; aunque en algunos casos los superaban en precio de forma considerable, llegando a duplicarlos. Evidentemente la influencia indígena era más fuerte en el Valle Central de Chile que en las pampas rioplatenses. De allí la mayor calidad y precio de los ponchos.

Desde el punto de vista de la procedencia, los registros compulsados incluían cuatro categorías: indiano, pehuenche, arribanos e inglés. La noción indianos hace referencia a los pueblos indígenas, principalmente mapuches. En la cultura colonial, signada por la minimización de las culturas originarias, predominaba una tendencia a invisibilizar el origen indígena de los productos; por este motivo, los ponchos indígenas estaban subregistrados en los documentos. Tal vez por este motivo, solo se anotó un caso de poncho "indiano".

Junto con los "ponchos pehuenches", el origen étnico se visibilizaba en los "ponchos arribanos". En el siglo XVII se usaba el concepto "indios de arriba" para denominar a los que provenían de la Araucanía, al sur del Biobío (Valenzuela, 2014). En el contexto de las fuentes consultadas, la expresión "arribanos" se refiere probablemente a ponchos tejidos por los indígenas situados en el espacio mapuche. Los "ponchos arribanos" se registraron en cinco casos, incluyendo los de precios más altos. Ello muestra cómo, a pesar de la hegemonía política y militar de los espańoles, los tejidos indígenas lograron mantener su reputación en el Reino de Chile.

Los ponchos ingleses, en cambio, tuvieron una presencia menor: solo se registraron dos casos (1826 y 1835); uno de ellos de hilo con cinta a la boca; solo en un caso se registró el precio, y fue regular (8 pesos). Este fenómeno fue detectado dos décadas más 
tarde por el viajero británico Smith. Al recorrer la zona centro-sur de Chile, Smith se asombró al comparar la superior calidad de los ponchos indígenas y mestizos, sobre los tejidos ingleses:

Con todos los adelantos de la ciencia moderna, los telares más célebres de Europa no han podido igualar las telas producidas por la maquinaria más primitiva. No sólo permanecen sin rivales los chales del oriente, pero aun la frazada sudamericana no ha podido imitarse con éxito. Todos los años envían los fabricantes ingleses gran número de ponchos a Chile, pero no pueden equivocarse con los nacionales; aunque su textura es más fina y sus colores más suaves, no duran lo mismo, y la lluvia los traspasan con facilidad, en tanto que, los hechos en el país, al mojarse un poco, se ponen tiesos y compactos, lo que permite que la lluvia corra de la misma manera que por sobre el techo de una casa, protegiendo así al que los usa (Smith, 1855, p. 22).

A pesar de su superioridad tecnológica y económica, los ingleses no fueron capaces de superar la calidad de los tejidos indígenas de Chile.

\section{El micromundo del poncho pehuenche (1738-1806)}

Mayor recurrencia presenta el origen étnico de ponchos pehuenches: 27 casos. El poncho pehuenche era un producto típico, cuyo anclaje no era geográfico sino cultural: su identidad no dependía de un lugar específico, pero sí de un pueblo relativamente móvil, que circulaba por las amplias mesetas y valles cordilleranos.

Las tribus pehuenches integradas a los circuitos comerciales hispanos habitaban en las laderas de la cordillera de los Andes, entre el Maule y el Biobío, principalmente. Sostenían activas redes comerciales tanto hacia el Atlántico como hacia el Pacífico. Los ponchos eran uno de sus principales productos de intercambio, junto con la sal y el ganado. Según el historiador Mario Góngora, "anualmente, estos naturales salían al Valle Central de Chile, trayendo ponchos, brea, plumas de avestruz y, sobre todo, la sal del sur de Cuyo" (Góngora, 1966, p. 23). Los comerciantes hispanocriollos viajaban a Malargüe a fines del siglo XVIII para adquirir ponchos pehuenches y remitirlos al mercado chileno (León, 2000). En los corregimientos de Colchagua y Rancagua los ponchos pehuenches encontraron un mercado capaz de valorarlos y pagar un alto precio por ellos.

Incluso, como lo demuestran diversos testimonios judiciales, se arriesgaba la vida para conseguirlos. En 1753, en una causa criminal iniciada en la localidad de Cauquenes, uno de los testigos declaró contra el principal acusado: "que ahora pocos días pasó el dicho Hormazábal para Tucapel con unos caballos y que trajo dos ponchos pehuenches buenos de precio, uno cari azul y otro negro, los que le vio este testigo" ${ }^{16}$ Otros, señalaba el cronista jesuita Miguel de Olivares, más que robar por necesidad, "roban para negociar lo robado y para dar fomento a los vicios... se vacían un potrero de caballos de que se llevan ciento o doscientos, y por sendas escusadas o caminando de noche, los transportan tres o cuatro días en distancias de 100 leguas, llevándolos muchas veces a tierras de indios para trocarlos por ponchos, que es comercio aquí muy usado" (Olivares, 1766, p. 181). De similar opinión fue el jesuita Antonio Sors, quien señalaba en esos mismos años que para mantener la paz se debía vigilar "que los comerciantes o conchavadores no lleven géneros prohibidos a los indios por la codicia de sus ponchos". ${ }^{17}$ En 1738, las autoridades interrogaron a Miguel de Matamala, acusado de participar de una red de comerciantes y oficiales de fuertes que importaban estos productos: "Responde que todos los año de cuatro a esta parte, le imbiaba el referido Saldías al declarante dos o tres veces a los Pehuenches a venderles vino, añil, sombreros y otras cosas y cuarenta yeguas una vez, y que de estos géneros le traía ponchos". ${ }^{18}$ Pedro de Oñate,

16 Declaración de Antonio Salgado ante el juez de comisión de la doctrina de Cauquenes, Villa de Cauquenes, 6 de julio de 1753, en Causa criminal contra Cristóbal Hormazábal por abigeato. AN, FJT, Legajo 228, pza. 10.

17 Antonio Sors, "Historia del Reyno de Chile, situado en la América meridional" (1780). Revista Historia y Geografía 48 (Santiago, 1922), p. 280.

18 Declaración que hace Miguel de Matamala, nativo del Partido de la Estancia del Rey, asistente en Antuco, dentro 
testigo en el mismo caso judicial, apuntó que "entre los dos conchavadores [trajeron] veinte ponchos balandranes" ${ }^{19}$ En otro bullado caso judicial referido a estos mismos temas, se lee: "Añade el declarante que pasó esta primavera a comerciar con los pehuenches de orden de su Cavo y con licencia que manifestó del sargento mayor del reino, y que de sus contratos consiguió doscientos y veinte pesos fuera de una fuente de plata y ocho ponchos, todas dichas especies para don Joseph Cruzat". ${ }^{20}$ Laureano Bueno, comandante del recién fundado fuerte de Santa Bárbara, localidad vecina a los pehuenches, fue acusado en 1769 de tener "frecuente comercio con los indios infieles internándoles por terceros personas no solo yeguas, sino también recuas de vino a conchabo de ponchos.... ${ }^{21}$

El activo comercio de ponchos con los pehuenches hizo asequible ese producto a los habitantes de Chile central. En efecto, en este territorio de Rancagua y Colchagua se registraron 27 ponchos pehuenches entre 1761 y 1806 . Particular interés tienen dos registros de partidas numerosas, una de 10 ponchos pehuenches registrada en la estancia de Boldumahuida (1761) y otra de 11 unidades en casa de Rosa de Salinas (1776), ambas en Colchagua. A ellos se sumaron otros seis registros individuales, todos ellos distribuidos entre Rancagua y Colchagua.

Los ponchos pehuenches se caracterizaban por sus colores y su buen precio de mercado. Los registros señalan que normalmente, estos ponchos eran color verde, azul o negro. Su valor oscilaba entre 6 y 7 pesos. En caso de estar comido de polilla, su valor caía

de la Cordillera, en esta Plaza de Yumbel, donde juró a Dios y a una señal de Cruz decir la verdad de lo que le fuese preguntado, Yumbel, 16 de abril de 1738. AN, Fondo Capitanía General (FCG), vol. 48, f. 401.

19 Declaración jurada del capitán don Pedro Cofré, 26 de enero de 1737. AN, FCG, vol. 48, f. 399.

20 Declaración del capitán Juan de Molina, Yumbel, 6 de marzo de 1750, en Auto del gobernador Domingo Ortiz de Rozas. Sobre un asalto de los indios en el año 1749 en el camino de Mendoza a Buenos Aires, Yumbel, 6 de marzo de 1750. AN, FCG, vol. 294, fs. 395v.

21 Declaración de don Fructuoso López, vecino de Santa Bárbara, ante el obispo Ángel Espiñeira, Concepción, 3 de enero de 1769, en Criminales seguidos contra el teniente Don Laureano Bueno por cierta y ilícita amistad, y comercio con los indios. AN, FCG, vol. 300, f. 137. a 4 pesos. No alcanzaba el tope de gama de los ponchos, pero se ubicaba en un segmento de precios interesante: un poncho pehuenche valía más que una vaca, es decir, a valores actuales, más de mil dólares.

Los datos aportados por las fuentes permiten realizar interpretaciones de interés. En primer lugar, estas cifras estaban muy lejos de los elevados precios insinuados por Llorca. En Colchagua y Rancagua, un poncho pehuenche tenía un valor equivalente a una vaca o una yegua; no 15 ni 20 unidades. El precio de tasación se asemejaba al detectado por Garavaglia para los ponchos de Santiago del Estero, los cuales se consideraban de buena calidad, al contar con colores brillantes, y bellos diseños. De acuerdo a la evidencia, los ponchos pehuenches estaban dentro de ese selecto grupo tan apreciado como los del espacio trasandino.

El ciclo histórico de los ponchos pehuenches es otro tema interesante. En los registros judiciales del Maule, estos abrigos se registraron con frecuencia en el segundo tercio del siglo XVIII. Luego, en el tercer tercio de esa centuria, se popularizaron en los corregimientos de Colchagua y Rancagua. El último registro corresponde a la capital de esta última en 1806. En líneas generales, se puede concluir que el ciclo histórico del poncho pehuenche corresponde al período colonial tardío, particularmente entre 1738 y 1806. Al parecer, los españoles supieron valorar la calidad de estos tejidos; no así los patriotas que asumieron el poder después de la revolución.

\section{Las mantas y su presencia}

Junto con los ponchos, las mantas también tuvieron una presencia considerable en la región. Las fuentes revelaron 108 registros de mantas, lo cual representa una frecuencia superior en un $50 \%$ con respecto al poncho. De todos modos, el concepto de manta se usaba para una gama muy amplia de tejidos, desde los más básicos, tasados en un peso, hasta las mantas de labor, de trabajo intensivo y precios más altos.

Las mantas se destacaban por sus colores. Tal como apreciaron los viajeros, estos tejidos de origen indígena causaban un impacto visual considerable. Las fuentes consultadas entregan información precisa 


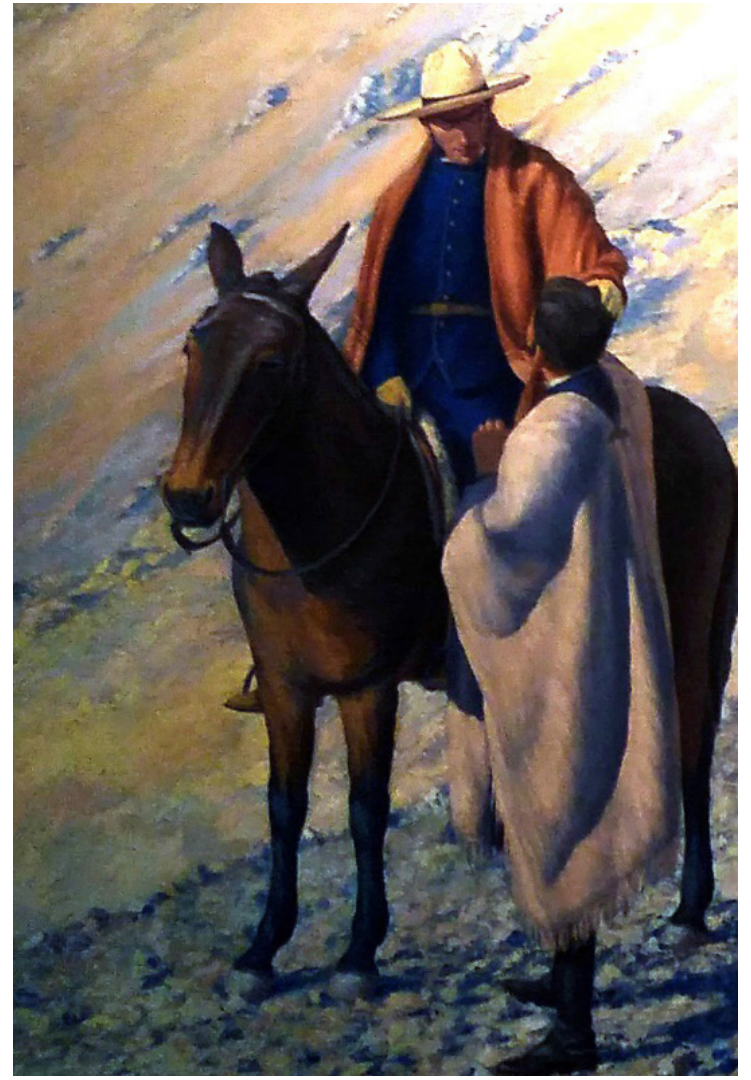

Figura 1. Fidel Roig Matons. Regreso del general San Martín y encuentro con Olazábal (fragmento) (óleo sobre tela en bastidor, 297 x 205 cm). Pinacoteca del Concejo Deliberante de la Ciudad de Mendoza.

sobre el tema. Igual que los balandranes y los ponchos, los colores más frecuentes de las mantas eran el azul (18 casos) y el blanco (ocho casos). Estos representaban cerca del 75\% del total. La novedad se encuentra en el ascenso del color negro (cuatro casos) que se desprendía de los demás colores, y se ubicaba como el tercero más recurrente entre las mantas regionales. En menor medida aparecían mantas de color negro (cuatro casos), colorado, verde y carey.

Desde la perspectiva de los precios, se nota una diferencia considerable con los ponchos. Sobre todo porque las mantas tenían una presencia importante en el segmento más barato. Sobre un total de 71 mantas registradas con sus precios, había 44 mantas de 1 peso y 14 de 1,5 pesos. Por lo tanto, en este conjunto de mantas baratas se encontraban $58 \mathrm{ca}-$ sos, lo cual representa el $76 \%$ de la muestra. Para estandarizar el análisis con la escala elaborada para los

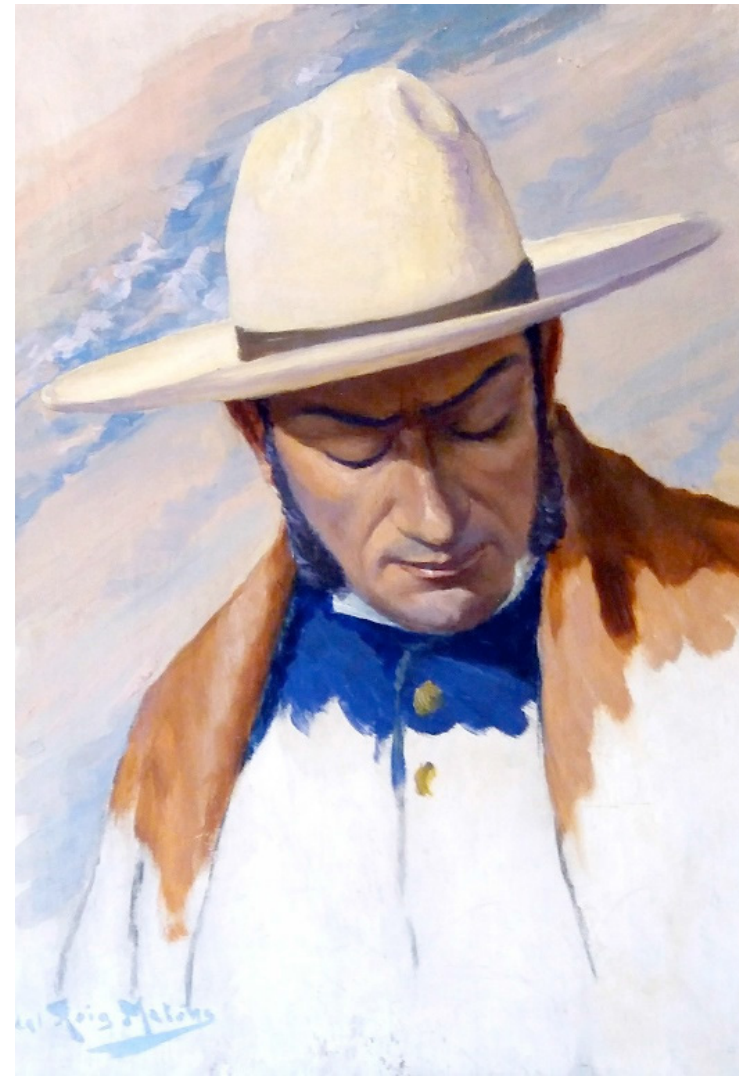

Figura 2. Fidel Roig Matons. Estudio de Expresión (óleo sobre hardboard, $40 \times 54 \mathrm{~cm}$ ). Pinacoteca del Concejo Deliberante de la Ciudad de Mendoza.

ponchos, debemos añadir las mantas de 2 pesos (tres casos), 2,5 pesos (tres casos), 3 pesos (tres casos) y 4 pesos (cuatro casos). Como resultado, el grupo de mantas baratas reúne 71 casos y representa el $82 \%$ de la muestra.

Junto con las mantas baratas, se usaban también mantas de calidad. En la escala general de precios de tejidos regionales, las mantas de calidad se encontraban en el nivel medio (entre 5 y 9 pesos). Dentro de esta categoría se registraron 15 mantas (17\%). Éstas alcanzaban el estatus y apreciación de los ponchos pehuenches. Y no había mantas de precio alto ni de tope de gama.

Las mantas de calidad tenían atributos apreciados por el mercado. Con frecuencia se trataba de mantas de labor (26 casos). Estaban decoradas con bordados y guarniciones; con frecuencia eran paleteadas 
(11 casos). Los diseños incluían guardas lineales (listadas). Las labores se realizaban con punto autora, punto real y puntas voladas y acentadas. Las tejedoras y tejedores cuidaban todos los detalles para ofrecer prendas de la más alta calidad.

\section{Del chamal al chamanto}

Las actuales chamanteras, al ser consultadas sobre el origen de la palabra chamanto, señalan que proviene de las palabras "chamal" y "manto". En los diccionarios especializados, también se ha recogido esta idea. Tal como se ha mencionado antes, la Academia Argentina de Letras sostiene que la voz chamanto proviene "del araucano chamal y manto" (AAL, 2003, p. 202). En las fuentes notariales y judiciales compulsadas para la presente investigación, no se ha encontrado el uso del concepto "chamal". Pero sí se usaban las palabras "chamalto" y "chamanto" como sinónimos, sobre todo en la primera mitad del siglo XIX.

De todos modos, las memorias de la época sí incluyen el uso del concepto "chamal" como eslabón perdido entre el balandre, el poncho y el chamanto. El caso más interesante se encuentra en el libro de Manuel de Olazábal, referido a sus recuerdos durante las guerras de la independencia; el autor escribió sobre el regreso del general San Martín a la Argentina, después de las campañas libertadoras en Chile y Perú (febrero de 1823). San Martín viajó de Santiago a Mendoza por la ruta del Cajón del Maipo. Olazábal lo fue a recibir al boquete del Portillo, y lo esperó con unos mates.

San Martín se presentó en el lugar con vestimenta típica: llevaba un sombrero de paja de jipijapa (Ecuador). Como abrigo, "el chamal (poncho) chileno cubría aquel cuerpo de granito, endurecido en el vivac desde sus primeros años" (Olazábal, 1864, p. 60). Este testimonio fue utilizado más tarde con fines artísticos. El pintor Fidel Roig Matons tuvo en cuenta estos datos para pintar el cuadro de composición Regreso del general San Martín y encuentro con Olazábal en el Portillo (óleo sobre tela en bastidor, 297 x $205 \mathrm{~cm}$ ) (Figura 1), y el Estudio de expresión para el cuadro anterior (óleo sobre hardboard, $40 \mathrm{x}$ $54 \mathrm{~cm}$ ) (Figura 2).
La decisión de San Martín, de usar un sombrero de paja y un chamal en el momento de regresar a su patria, después de las campañas libertadoras, fue una decisión de alto valor simbólico: consideró que esa identificación con los productos típicos campesinos era el mensaje que consideró más adecuado para entregar a las élites de su país.

\section{Los chamantos en Rancagua y Colchagua (1821-1850)}

Como resultado de la evolución de los textiles durante el período colonial, se produjo el surgimiento del chamanto. Éste se concretó, finalmente, a comienzos del siglo XIX, poco después de la independencia. En cierta forma se puede decir que el chamanto chileno "nació con la patria". El primer registro corresponde a un registro de Rancagua (1821), cuando se anotó un chamanto de lana verde. $\mathrm{Al}$ año siguiente se registraron otros dos chamantos en Viluco (comuna de Paine), uno valuado en 7 pesos y el otro en 2 pesos.

Como se puede advertir de estos precios, los primeros chamantos surgieron como prendas relativamente modestas y populares. No tenían pretensiones señoriales ni se asociaban al prestigio ni el lujo. Tenían una finalidad práctica y utilitaria: abrigar, proteger del frío. En cierta forma, la sociedad mestiza de Chile daba continuidad a la tradición indígena del poncho, el unkun; y el macuñ; a la vez, se recuperaba la tradición del original y modesto balandre espańol, usado por los campesinos durante el reinado de Alfonso X. Durante el siglo XIX, el chamanto chileno conservó este perfil campesino y popular. Y ésa fue, justamente, la identidad que captó Zorobabel Rodríguez en 1875 , tal como ya se ha señalado.

En el presente estudio se detectaron 63 chamantos entre 1821 y 1848. Se formó así un corpus documental de singular riqueza a través del cual, se han podido conocer las tres primeras décadas de desarrollo de este singular tejido en el tercio norte del Valle Central de Chile.

La propagación del chamanto por los territorios de Rancagua y Colchagua fue veloz y universal. Dos años más tarde, el chamanto llegó también a San 
Fernando (1824). Poco después se registró en Coinco (1826), Río Claro (1829), Los Parrones (1831), Peumo y Machalí (1835). Unos años más tarde se protocolizó el primer registro en el secano, particularmente en La Estrella (1842). En dos décadas, el chamanto había llegado a prácticamente todo el tercio norte del Valle Central. Para completar el cuadro, conviene señalar que el primer registro de Doñihue corresponde a 1863.

El desarrollo de una línea de chamantos de alta calidad, elevado precio y diferenciación social comenzó a mediados de la década de 1850, cuando algunos hacendados comenzaron a impulsar tejidos locales con fibras traídas desde Europa. Al principio, se traían franelas inglesas y francesas a Chile, donde se deshilaban para obtener las hebras que luego se usaban para los chamantos. Este aspecto fue detectado por un viajero inglés, Edmond Reuel Smith (18291911), durante su viaje al Valle Central de Chile, realizado en 1855 y publicado 60 años más tarde (Smith, 1914). Su relato es ampliamente conocido y citado en la literatura especializada (Alvarado y Guajardo, 2011; Castro et al., 2017). De todos modos, la referencia es muy valiosa para el tema que estamos tratando, motivo por el cual, conviene reproducirla completa:

Me sorprendió saber que los colores brillantes que muestran aquellos tejidos y que tanto llaman la atención de los extranjeros, no son tejidos por los naturales, cuyos tintes son, en la mayor parte, sombríos: café o azul obscuro. La lana escarlata y otras de colores brillantes que usan para adornar sus ponchos, se obtienen deshilando las franelas inglesas o francesas. Las hebras delgadas que así se procuran son después torcidas unas con otras, hasta conseguir un hilo del grueso necesario. Había en el telar una chamanta-nombre que se da a ponchos que se componen nada más que de listones de colores diversos -el cual me llamó especialmente la atención a causa de su fina textura y hermoso trabajo. Había sido mandada hacer, y el dueño había escogido el dibujo y entregado los materiales. $\mathrm{Su}$ valor intrínseco sería, más o menos, de \$34, una vez terminada. La pobre nińa calculaba que demoraría cuatro meses en terminarla e iba a recibir por su trabajo la suma de $\$ 12$ (Smith, 1855, pp. 21-22).

El procedimiento detectado por el viajero británico es particularmente significativo. Sobre todo porque fue testigo de las fuentes de un curso cultural que con el tiempo se desarrollaría con mayor fuerza. Las élites hacendales del Valle Central rescataban la capacidad de trabajo de las tejedoras locales, y a la vez, trataban de distinguirse con el uso de materiales importados de Europa, más vistosos; la idea de conjugar estos dos elementos, marcaría la identidad del chamanto en los 150 ańos posteriores.

Se puso en marcha así un proceso interesante de nueva hibridación cultural entre el producto mestizo y las hebras industriales europeas. Además, se fortaleció la tradición de convivencia de dos calidades de chamanto: una línea de carácter popular y utilitario, y otra más señorial y de prestigio. Esta diferenciación fue captada en el corpus documental examinado en la presente investigación.

En efecto, los registros muestran detalles de calidad en los chamantos. Varias veces se menciona que se trata de chamantos "de labor", concepto usado también para las mantas. Además, se menciona que los chamantos tenían flecos (dos casos). También se lo califica de "fino" y "de guarda", seguramente por la ornamentación. Otra nota saliente aparece en el desarrollo de una línea infantil: las fuentes registraron 12 chamantos de niño, lo cual marca también una diferencia notable con balandranes, mantas y ponchos.

Desde la perspectiva de los precios, se percibe que, en el siglo XIX, el chamanto se encontraba en proceso de desarrollo. Las fuentes entregan información de 56 casos ( $89 \%$ de la muestra). Ello incluía 44 chamantos para adultos y 12 chamantos infantiles. Estos últimos se valuaron a 9 pesos la docena. Dentro de los chamantos adultos, en la categoría de valor bajo (uno a 4 pesos) se registraron 23 ejemplares $(52 \%)$. Se incluían en este grupo los chamantos viejos, servidos y de regular estado. En nivel medio de precios (5 a 8 pesos) se registraron 19 ejemplares. En ellos se destacaba su calidad "de labor". En la cúspide de la pirámide aparecieron dos chamantos: uno bueno en 10 pesos (Chimbarongo, 1846) 
y otro "fino sin usar" en 20 pesos (San Fernando, 1843). Estos datos confirman la intuición de Zorobabel Rodríguez: el chamanto del siglo XIX era, principalmente, una prenda popular y utilitaria. Muy pequeño era todavía el segmento de chamantos asociados a los valores del estatus y la elegancia de las élites, como había detectado Smith en 1855, en el ejemplar valuado en 34 pesos. Por este motivo, en la muestra examinada en esta investigación se detectó solo un chamanto de alto valor.

Igual que los ponchos y mantas, los chamantos atraían por sus colores. Las fuentes entregan precisión sobre el color de 18 chamantos $(28,5 \%$ de la muestra). El más frecuente era el azul, con 10 casos (57\%). Le seguían en importancia los tejidos de color blanco (cuatro), negro (tres) y verde (uno). Interpretados en el contexto histórico, se detecta que los colores del chamanto se mantuvieron como continuidad de los balandranes, los ponchos y las mantas, con el predominio de los colores azul y blanco, a los cuales se sumaba el negro, el cual ya había demostrado su vigor en el desarrollo de las mantas. Se presentaba entonces una línea de continuidad en los colores típicos de la región, con predominio de azul, blanco y negro para la ropa masculina. Estas tonalidades se diferenciaban claramente de la ropa femenina, signada por las mantillas de bayeta, en las cuales predominaban los colores amarillo y morado. Estos matices se encuentran ausentes en los balandranes, ponchos y chamantos. Los colores más brillantes, sobre todo el rojo, detectados por Smith en 1855 , a partir de fibras importadas de Francia e Inglaterra, todavía no estaban arraigados en la corriente principal de las chamanteras.

\section{Tiempo de tejer entre Rancagua y Colchagua}

Los balandranes, ponchos, mantas y chamantos tenían fuerte presencia en Rancagua y Colchagua. Sus habitantes no se limitaban a lucirlos y abrigarse con ellos. También se ocupaban de todo el proceso productivo, incluyendo la cría del ganado ovino, la esquila, el hilado y el tejido. La literatura especializada ya se ha encargado de demostrar la relevancia central que tenía la ganadería en esta región, particularmente el ovino (Muńoz, 2010). A ello hay que añadir la profunda tradición del tejido, que todavía no ha sido estudiada en profundidad.

Los telares fueron parte importante del paisaje cotidiano de las haciendas y casas de campesinos de Rancagua y Colchagua durante los siglos XVIII y XIX. Los inventarios de bienes han registrado más de un centenar de telares, distribuidos entre las distintas ciudades, villas y caseríos, desde 1680 hasta el siglo XIX. La alta demanda de tejidos abrió posibilidades para diversos tipos de trabajos, con lo cual, los telares debían estar adaptados a distintas necesidades.

Los telares de este territorio estaban especializados para diversas tareas. Había telares para ponchos y para mantas; telares para bayeta o para tocuyo. Se usaba en ellos madera de patagua con horcones de espino; también contaban con quilbo, lanzada y caja de dos o tres peines. Las calidades y precios del telar podían variar entre uno y 7 pesos. En líneas generales, el telar era un instrumento de trabajo de relativamente bajo costo, y estaba al alcance de los sectores populares, tanto mestizos como indígenas.

Los telares se usaban intensivamente en Colchagua y Rancagua. Se insistía mucho en controlar que contaran con todo el equipamiento necesario para realizar las tareas. Las fuentes revelan el cuidado que ponían las tejedoras para mantenerlos en buenas condiciones. En los inventarios de bienes, al describir los telares se reiteran expresiones como "completo", "bien aviado", "bien aperado", "con todo aperado", "con todo su aderezo" o "con todos sus aperos necesarios". En muchos hogares campesinos, el telar ocupaba un lugar central tanto en el cuidado como en la valoración.

Los telares estaban asociados a emprendimientos de pequeñas empresas familiares. No había en la región grandes fábricas de tejidos industriales, como en Liverpool o Manchester. Al contrario, la producción textil estaba distribuida en múltiples emprendimientos. Las propiedades mayores podían tener más de un equipo; pero de ninguna manera lograban generar concentraciones significativas. Por ejemplo, la hacienda Bucalemu, la más rica de Chile, tenía siete telares; pero representaba menos del $5 \%$ de la capacidad instalada regional. De esta manera, 
la actividad textil era una rama de la economía más bien asociada a la economía doméstica y la cultura del trabajo, antes que a la concentración del capital.

El telar facilitó la integración social pues, con una pequeña inversión inicial, a través de su trabajo, podían lograr una inserción satisfactoria en la vida social del espacio hispanocriollo. Escapa a los objetivos de este artículo detallar el papel de las tejedoras en esta región. Pero bastan algunos documentos para dejar constancia de su protagonismo. En efecto, las haciendas más aristocráticas, junto con lucir los mejores y más elegantes balandranes, impulsaban su tejido por parte de los artesanos. Así se desprende del protocolo elaborado con motivo de la partición de bienes de don José Quezada (1774). En el inventario de sus bienes se anotó lo siguiente:

\section{[...] un balandrán blanco y otro casi decen- te ambos del uso del dicho difunto que se vendieron en 56 pesos; un balandrán blan- co flamante que se halla en poder de don Santiago Quezada nuestro hermano, y otro poncho pehuenche que el suso dicho compró en esos tiempos con más otro balandrán de precio, que se está tejiendo. ${ }^{22}$}

Resulta notable la fuerza de este documento: se trata de una familia aristocrática del Valle Central de Chile, que tiene un aprecio particular por los tejidos. El hacendado José Quezada poseía dos balandranes de muy alta calidad. Después de su muerte, y a pesar de estar usados, ambos fueron vendidos a un promedio de 28 pesos cada uno, lo cual equivalía aproximadamente a cinco o seis vacas. Más valioso todavía era el balandrán "flamante" que tenía su hermano Santiago. Se trata de cifras sobresalientes, en la modesta sociedad de aquella época. Pero dentro de ese espacio, los balandranes tenían un lugar especial. Y no se adquirían en terceros mercados, sino que se encargaban a los artesanos, expertos tejedores, asentados en la estancia.

Otro documento ilustrativo de esta cultura corresponde al inventario de bienes de Pedro José Guzmán

22 Partición de bienes de don José Quezada, San Fernando, 1774. ANH, Fondo Judiciales de San Fernando (FJSF), Legajo 15, Pieza 2, Foja 5.
(1787). Después de su fallecimiento, se realizaron los procedimientos de forma para dimensionar sus bienes y distribuirlos entre sus herederos legítimos. Y una vez más, en este registro, se dejó constancia del protagonismo de las tejedoras locales:

[...] se pone por inventario 143 varas de bayeta, blanca las mismas que han producido las mitas de la lana, que salió de la trasquila de éste presente ańo, y la otra mitad la dio la viuda del finado, teniente coronel Pedro Joseph Guzmán, a varias mujeres para que la hilaran y tejieran y entregaran la ante dicha cantidad de varas de bayeta sin otro costo que haberles dado la mitad de la lana. ${ }^{23}$

La capacidad de trabajo de los campesinos contribuyó a generar cadenas de valor en toda la región. Los pastores se ocupaban de criar las ovejas y esquilar la lana; luego, las hilanderas se ocupaban de trabajarla para obtener los hilos; con éstos, los tejedores se aplicaban a sus telares para obtener ponchos, mantas, balandranes y finalmente, chamantos. Una economía popular que prosperaba al abrigo de una prenda de vestir tradicional que pronto se transformó en marca de identidad.

\section{Conclusión}

Los registros de fondos judiciales y notariales han permitido conocer aspectos significativos de la evolución de ponchos, balandres y chamantos, lo cual contribuye a complementar los testimonios de cronistas y viajeros, como así también, los estudios realizados a partir de colecciones e iconografías de los tejidos.

Las fuentes tienen una limitante ideológica: fueron elaborados por el sistema de registro establecido por el Imperio español, y tenía el consiguiente sesgo cultural, en el sentido de sobrevisibilizar los bienes, usos y costumbres de la sociedad española, y de invisibilizar los del mundo indígena. Este enfoque estuvo vigente en buena parte de la vida socioeconómica colonial, y se reflejó con la prioridad del trigo sobre

23 Inventario de bienes del teniente coronel Pedro José Guzmán, San Fernando, 5 de noviembre de 1787. ANH, FJSF, Legajo 24, Pieza 2, fs.15v-16. 
el maíz y la quínoa; la oveja sobre llamas y alpacas; y del balandre sobre el makuñ. Este concepto fue detectado y registrado por Ovalle en 1646; pero en las escrituras notariales y judiciales de los dos siglos posteriores, se dejó de usar. En cambio, los escribanos sí utilizaban con familiaridad el concepto de balandre.

De todos modos, la cultura indígena logró abrirse camino en los registros españoles. Se usaron expresiones como "ponchos pehuenches" o "ponchos de arriba”, para indicar los orígenes étnicos o geográficos de estos tejidos. También se empleó el concepto "pocho balandre", símbolo de la cultura híbrida que se construyó con el mestizaje biológico y cultural.

Este producto típico chileno, que actualmente goza del reconocimiento como DO y altos valores de mercado, fue resultado de un largo proceso cultural, de seis siglos de mestizaje y adaptación, desde los labradores españoles de la época del rey Alfonso X y los makuñ de los indígenas chilenos, hasta los campesinos del Valle Central de Chile y las brillantes hebras de las franelas europeas de mediados del siglo XIX.

Resulta notable el paralelismo entre el makuñ o poncho indígena, el balandre español y chamanto chileno. Ambos nacieron como prendas utilitarias para abrigar a los campesinos durante sus labores del campo. Eran tejidos cuadrados con un orificio en el medio para introducir la cabeza; sus costos eran bajos y predominaba la función sobre la forma. El arraigo de estas prendas entre los labradores las convirtió en símbolos culturales, y con el tiempo, comenzaron a ascender en la jerarquía social. En España, el balandre pasó de prenda de labradores y penitentes en el siglo XIII, a indumentaria eclesiástica y estudiantil en el XVIII; en Chile, el poncho indígena ascendió hasta alcanzar los más altos niveles de reputación social, particularmente los llamados "ponchos arribanos", tejidos directamente en la Araucanía, al sur del Biobío. Finalmente, el chamanto pasó de abrigo popular campesino a comienzos del siglo XIX, a indumentaria señorial de los huasos corraleros, 150 años más tarde. En ambos casos, la movilidad ascendente de esta prenda está asociada a su legitimidad como símbolo de la cultura del trabajo en el mundo campesino.

La tradición textil de los ponchos, chamantos, mantas y balandranes, formó una rama significativa en la vida social y económica de los campesinos chilenos; participaron de ella indígenas, mestizos y europeos hispanocriollos, fundamentalmente pequeñas empresas familiares asociadas al telar y la cultura del trabajo. Más que el capital, en esta actividad lo importante era el conocimiento y el dominio de la técnica, lo cual se transmitía de generación en generación. Además, estos tejidos impulsaban cadenas de valor con otras actividades económicas, como la cría de ovejas, la elaboración de quesos y el comercio de la sal de Cáhuil, entre otras. En realidad, aquellos tejidos eran parte de toda una cultura campesina existente en el Valle Central.

La actitud de las élites frente a los productos campesinos muestra cambios a lo largo del tiempo. Entre el siglo XVII y mediados del XIX, las élites chilenas valoraban el trabajo de las tejedoras campesinas, tanto indígenas del sur como mestizas del Valle Central; por este motivo, las élites generaron un mercado para los textiles de alta calidad. Y las campesinas tenían la posibilidad de desplegar toda la capacidad de su arte para elaborar tejidos superiores, de labor, bordados y muy bien teñidos con colores permanentes, además de diseños atractivos. El trabajo intensivo que requerían estas prendas era reconocido por las élites con precios elevados, lo cual hacía posible su existencia.

El período de apogeo de los tejidos regionales (ponchos, chamantos, mantas y balandres) coincide con el auge de los productos típicos, indumentarios (chupallas, sombreros de jipijapa) y gastronómicos. Entre ellos se incluyen el queso de Chanco, el jamón de Chiloé, las longanizas y salchichones de Chillán, los quesos de Tafí, el chacolí (Doñihue), el asoleado de Cauquenes y Concepción, el aguardiente cuyano, el pisco de Coquimbo y Copiapó, entre otros. Las élites se sentían orgullosas de consumir y exhibir estos productos. Estas escenas se vieron en los días de la independencia, cuando el general San Martín lucía un sombrero de jipijapa y chamal chileno y en los banquetes de la patria, organizados por O’Higgins y Carrera, servían jamón de Chiloé, quesos de Chanco, y vinos locales como chacolí y asoleado de Concepción y Cauquenes. Por su parte, las longanizas y salchichones de Chillán quedarían grabados en batallas épicas como los sitios de Chillán (1813) y el Morro de Talcahuano 
(1818). Los productos típicos, con identidad de origen geográfico, tuvieron un papel central en la vida económica, social, cultural y militar entre fines del período colonial y el primer medio siglo de historia republicana.

La situación cambió en la segunda mitad del siglo XIX, con la imposición del paradigma francés y las modas británicas. Este giro de las pautas de consumo de las élites latinoamericanas en general y chilenas en particular, redujo drásticamente el mercado para los productos campesinos de alta calidad. En este contexto, la mayor parte de los productos típicos regionales desapareció. Algunos lograron permanecer, entre éstos, los ponchos, chamantos y mantas. Ellos son portadores de un profundo significado identitario y patrimonial.

\section{Agradecimientos}

CONICYT - Proyecto FONDECYT 1130096.

Gobierno Regional de O'Higgins. Proyecto FIC "Rutas de la Patria Nueva". Los autores agradecen también el aporte de Alejandro Salas, Camila Cáceres y Andrea García por el trabajo de relevamiento de fuentes en el Archivo.

\section{Referencias citadas}

Academia Argentina de Letras (2003). Diccionario del habla de los argentinos. Buenos Aires: Espasa, 609 pp.

Aguilera, P. (2016). El queso de Chanco: un producto típico de la industria popular de Chile (Siglos XVIII y XIX). Rivar, 3(8): 41-63.

Alvarado, I. y Guajardo, V. (2011). Mantas y mantos. Cubrir para lucir. Santiago: DIBAM, $102 \mathrm{pp}$.

Amat y Junientt, M. (1760). Historia geographica e hidrographica con derrotero general correlativo al Plan de el Reyno de Chile. Revista Chilena de Historia y Geografia, Santiago, 1927-1929, 53-62.

Brouwer, H. (1646). Relación de un viaja a la costa de Chile realizado por orden de la Compañia holandesa de las Indias Occidentales, en los años de 1642 y 1643. Reproducido en: Rojas, M. (antología). Chile: cinco navegantes y un astrónomo. Santiago: Zig-Zag, 1956, 121-155.
Carduza, F., Champredonde, M. y Casablanca, F. (2016). Paneles de evaluación sensorial en la identificación y caracterización de alimentos típicos. Aprendizajes a partir de la construcción de la IG del Salame de Colonia Caroya, Argentina. Rivar, 3(8), 24-40.

Carreño Palma, L. (2009). Relaciones fronterizas y violencia en la plaza fuerte de Valdivia, siglo XVIII. Espacio Regional, 2(6), 13-22.

Castro, A. (2016). Chicha y Sidra de manzana en Chile (1870-1930): manzanas con identificación de origen. Rivar, 3(9), 4-25.

Castro, A., Mujica, F. y Cussen, F. (2017). Chamantos y mantas corraleras de Doñihue: ascenso y consolidación de un textil con Denominación de Origen (1917-2016). Rivar, 4(11): 5-24.

Champredonde M. y González Cosiorovski, J. (2016) ¿Agregado de Valor o Valorización? Reflexiones a partir de Denominaciones de Origen en América Latina. Rivar, 3(9), 139-163.

Cherduti, S. y Nardi, R. (1961). Tejidos Araucanos de la Argentina. Cuadernos del Instituto de Investigaciones Folklóricas, 2, 97-182.

Cofré, C. (2016). Productos típicos chilenos a través de los registros del Inapi. Rivar, 3(9), 104-122.

Coluccio, F. (1964). Diccionario folklórico argentino. Buenos Aires: Luis Lasserre Editores (2 vols.), 510 pp.

Concha, J. (1717). Relación que hace el Doctor Don José de Santiago Concha, oidor de la Real Audiencia de Lima, al Excmo. Sr. Don Gabriel Cano, 15 de diciembre de 1717. Santiago: Biblioteca Nacional, Manuscritos Medina, vol. 178, 237-310.

Corcuera, R. (1999). Ponchos de las Tierras del Plata. Buenos Aires: Fondo Nacional de las Artes y Verstraeten Editores.

Corominas, J. (2000 [1961]). Breve diccionario etimológico de la lengua castellana ( $3^{a}$ edición, 1973; 10ª reimpresión, 2000), Madrid: Gredos, 627 pp.

Espejo, G. (1916 [1876]). El paso de los Andes. Crónica histórica de las operaciones del Ejército de los Andes para la restauración de Chile en 1817. Buenos Aires: La Facultad, 658 pp. 
Frézier, A. F. (1902 [1716]). Relación del Viaje por el Mar del Sur a las Costas de Chile y el Perú Durante los Años de 1712, 1713 y 1714. Santiago: Imprenta Mejia.

Garavaglia, J. (1986). La revolución industrial fallida en las pampas. Anuario IHES 1, 45-87.

Garavaglia, J. y Wentzel, C. (1989). Un nuevo aporte a la historia textil colonial: los ponchos frente al mercado porteńo 1750-1850. Anuario IEHS, 4, 211-241.

Gatica, M. (1995). Diccionario de regionalismos de la provincia de San Luis. San Luis: Fondo Editorial Sanluiseño, $414 \mathrm{pp}$.

Góngora, M. (1966). Vagabundaje y sociedad fronteriza en Chile (siglos XVII a XIX). Cuadernos del Centro de Estudios Socioeconómicos, Facultad de Ciencias Económicas, Universidad de Chile.

Gruzmacher, M. L. y Guajardo, V. (2009). Chamantos: artesania y tradición del campo chileno. Santiago:, Corporación Patrimonio Cultural de Chile [ilustraciones color].

Lacoste, P. (2008). Aguardiente cuyano. Ascenso y declinación del principal destilado del Cono Sur de América. San Juan, Cámara de Diputados de la Provincia de San Juan, 110 pp.

León Solís, L. (1990). Maloqueros y conchavadores en Araucania y las Pampas 1700-1800. Temuco: Universidad de La Frontera, 243 pp.

León Solís, L. (2000). Los señores de la cordillera y las Pampas. Los pehuenches de Malalhue 1770-1800. Mendoza: Universidad de Congreso, 315 pp.

Llorca, M. (2014). A reappraisal of mapuche textile production and sheep raising during the nineteenth century. Historia, 47(1), 91-111.

Menéndez Pidal, G. (1986). La España del siglo XIII leída en imágenes. Madrid: Real Academia de la Historia, 319 pp.

Molina, J. I. (1776). Compendio de la historia civil del reino de Chile. Santiago: Colección de Historiadores y Documentos para la Historia Nacional, 1901.
Muñoz, J. (2010). Tercio y quinto de bienes: destinación en testamentos otorgados en el corregimiento de Colchagua, reino de Chile. En Zapico, H. R. y Siegrist, N., (Coords.) Familia, descendencia y patrimonio en España e Hispanoamérica (pp. 103-128). Argentina: Universidad Nacional de Mar del Plata.

Olazábal, M. (1864). Episodios de la guerra de la independencia. Buenos Aires: Instituto Nacional Sanmartiniano (2a edición), 1978, 69 pp.

Olivares, M. (1766). Historia militar, civil y sagrada de lo acaecido en la conquista y pacificación del reino de Chile, desde la primera entrada de los españoles hasta la mitad del siglo Décimo Octavo de Nuestra Redención. Santiago: Colección de Historiadores y Documentos para la Historia Nacional, vol. IV, 1864.

Osan, M. y Pérez Sáez, V. (2006). Diccionario de americanismos en Salta y Jujuy (República Argentina). Salta: Arco Libros / Secretaría de Cultura, 894 pp.

Ovalle, A. (1646). Histórica relación del Reyno de Chile. Roma: Francisco Caballo, 455 pp.

Pedrotta, V., Tancredi, M., Mariano, M. y Endere, M. L. (2013). Tejiendo saberes: Patrimonio intangible, identidad y valoración social: el caso de Ercilia Cestac. Runa, 34(1), 91-112.

Pinto, J. (2000). De la inclusión a la exclusión. De la inclusión a la exclusión. Santiago: USACH, 248 pp.

Pueyrredón, M. A. (1863). Memorias inéditas de un coronel. Prólogo y notas de Alfredo Villegas. Buenos Aires: Kraft, 470 pp.

Real Academia Española (1991). Diccionario de la Lengua Española (21 a edición, 2 tomos). Madrid: Espasa, 2133 pp.

Real Academia Española (2002 [1726]). Diccionario de Autoridades. Edición facsimilar (3 vols.). Madrid: Gredos.

Rodríguez, Z. (1875). Diccionario de chilenismos. Santiago: Imprenta El Independiente, 481 pp.

Rosales, D. (1674). Historia general del Reyno de Chile. Flandes Indiano (2 tomos). Vicuña Mackenna, B. (Ed.). 1877-1878. Valparaíso: Imprenta El Mercurio. 
Smith, E. R. (1855). Los araucanos. Notas sobre una gira efectuada entre las tribus indigenas de Chile Meridional (tomo I). Santiago, Sociedad Chilena de Historia y Geografía. R. E. Latcham (Trad.). Santiago: Imprenta Universitaria, 1914, $241 \mathrm{pp}$.

Valenzuela, J. (2014). Indios de Arriba en Santiago de Chile según los registros de bautismo: entre el auge esclavista, la reconstrucción urbana y el abolicionismo, 1665-1685. Chungara. Revista de Antropología Chilena, 46(4), 625-636. 